Jurdimas (Jurnal Pengabdian Ke pada Masyarakat) Royal

Vol. 3 No. 2, Juli 2020, hlm. 115 - 122

DOI: https://doi.org/10.33330/jurdimas.v3i2.616

ISSN 2614-7912 (Print)

Available online at https://jurnal.stmikroyal.ac.id/index.php/jurdimas

\title{
PENINGKATAN KESEHATAN JIWA MELALUI PERAN KADER MENUJU KELURAHAN SIAGA SEHAT JIWA
}

\author{
Sambodo Sriadi Pinilih ${ }^{1}$, Estrin Handayani ${ }^{1}{ }^{*}$, Elza Shelviana ${ }^{1}$, \\ Evi Rositasari ${ }^{1}$, Maulana Azis ${ }^{1}$ \\ ${ }^{1}$ Jurusan Keperawatan, Fakultas Ilmu Kesehatan, Universitas Muhammadiyah Magelang, \\ email: estrinhandayani@ummgl.ac.id
}

\begin{abstract}
The problem of disability is now a global health problem. As a result of disability, problems affect the productivity and quality of health of individuals and the community. Persons with disabilities are not just people who have physical disabilities. People with mental disorders (ODGJ) are included in a group of people with disabilities. The stigma of Indonesian society that is still very strong regarding ODGJ is not as strong as that of other people with disabilities. This should not be allowed because it will result in a violation of dignity and value. The purpose of this activity is to establish and optimize the role of Mental Health Cadres (KKJ) in the community who are trained in the early detection of mental disorders in the community. This activity was carried out in the Magelang village in the Central Magelang subdistrict, Magelang city. With a population of 6,441 people, most of the community work in the Magelang village is working in the field of community services, government \& individuals. In the 2019 Magelang sub-district has 18 patients with mental disorders. The results of the activities of the formation of mental health cadres (KKJ) in the community trained as many as 15 active cadres and are able to conduct early detection of mental disorders in the community so that the number of ODGJ of Magelang village is known to be 34 people and there are 2 people at risk of mental disorders. After knowing the number of ODGJ cadres implementing to the community one of them by providing psychological knowledge for families and communities.
\end{abstract}

Keywords: disability; mental health cadres; mental disorders

\begin{abstract}
Abstrak: Masalah disabilitas saat ini menjadi masalah kesehatan global. Akibat adanya masalah disabilitas mempengaruhi produktivitas dan kualitas kesehatan perseorangan maupun masyarakat. Penyandang disabilitas bukan hanya orang yang mengalami kecacatan fisik saja. Orang dengan gangguan jiwa (ODGJ) termasuk dalam golongan penyandang disabilitas. Stigma masyarakat Indonesia yang masih sangat kuat mengenai ODGJ tidak sekuat pada penyandang disabilitas lainnya. Hal ini tidak boleh dibiarkan karena akan mengakibatkan pelanggaran martabat dan nilai. Tujuan dari kegiatan ini untuk membentuk dan mengoptimalkan peran Kader Kesehatan Jiwa (KKJ) di masyarakat yang terlatih dalam melakukan deteksi dini kasus gangguan jiwa di masyarakat. kegiatan ini dilakukan dengan metode pendampingan kepada kader serta membantu para kader yang telah melakukan pelatihan tentang kesehatan jiwa. Dalam melakukan deteksi dini gangguan jiwa dimasyarakat dan pemetaan rumah penyandang disabilitas. Hasil kegiatan terbentuknya Kader Kesehatan Jiwa (KKJ) di masyarakat yang terlatih sebanyak 15 kader aktif dan mampu melakukan deteksi dini gangguan jiwa dimasyarakat sehingga diketahui jumlah ODGJ kelurahan magelang sebanyak 34 orang dan resiko gangguan jiwa ada 2 orang. Setelah diketahuinya jumlah ODGJ kader melakukan implementasi ke masyarakat salah satunya dengan cara memberikan pengetahuan psikologis bagi keluarga dan masyarakat.
\end{abstract}

Kata Kunci: disabilitas; gangguan jiwa; kader kesehatan jiwa 
Available online at https://jurnal.stmikroyal.ac.id/index.php/jurdimas

\section{PENDAHULUAN}

Meskipun bukan penyebab utama kematian namun masalah disabilitas saat ini sudah menjadi masalah kesehatan global bagi setiap negara termasuk Indonesia. Dikarenakan disabilitas mempengaruhi produktivitas dan kualitas kesehatan perseorangan maupun masyarakat, menimbulkan penderitaan yang mendalam bagi individu dan beban berat bagi keluarga baik mental maupun materi karena penderita menjadi tidak produktif (Kiesswetter, 2019). Secara sosial dampak yang muncul sangat serius berupa penolakan, pengucilan dan dampak ekonomi berupa hilangnya hari produktif bagi klien maupun keluarga yang harus merawat serta tingginya biaya perawatan penyandang disabilitas. Penyandang disabilitas bukan hanya orang yang mengalami kecacatan fisik saja. Orang dengan gangguan jiwa (ODGJ) termasuk dalam golongan penyandang disabilitas seperti yang tertuang dalam pembukaan pokok-pokok isi Convention on The Rights of Persons With Disabilities (CRPD), penyandang disabilitas yaitu orang yang memiliki keterbatasan fisik, mental, intelektual atau sensorik dalam jangka waktu lama, yang nantinya akan mempengaruhi dalam hubungan sosialnya sehingga rawan terjadi diskriminasi oleh lingkungannya (Cheung, 2017).

$$
\text { Riset Kesehatan Dasar Indonesia }
$$

2013 menunjukkan 1.728 orang memiliki gangguan jiwa berat, prevalensi menunjukkan 1,7 permil. Peringkat pertama yaitu DI Yogyakarta dan Aceh, peringkat kedua terdapat di Sulawesi Selatan, peringkat ketiga terdapat di Bali, dan peringkat ke empat terdapat di Jawa Tengah. (Kementrian Kesehatan, 2013). Presentase gangguan mental emosional (GME) di kawasan
Jawa Tengah menurut data Riset Kesehatan Daerah (RISKESDA) tahun 2007 dan 2013 menunjukkan jumlah Angka presentase penderita GME yang tinggi diperkirakan karena penduduk di daerah Jawa Tengah pada umumnya mayoritas tinggal di daerah pedesaan atau di daerah rawan bencana dan kurang mencukupi pemenuhan fasilitas dan pelayanan kesehatan bagi masyarakat khususnya kesehatan jiwa (Pinillih, 2017).

Stigma masyarakat Indonesia yang masih sangat kuat mengenai ODGJ tidak sekuat pada penyandang disabilitas lainnya. Hal ini tidak boleh dibiarkan karena akan mengakibatkan pelanggaran martabat dan nilai yang melekat pada tiap manusia oleh masyarakat dan mungkin pemerintah.Yang menganggap bahwa manusia merupakan satu kesatuan yang utuh yaitu "JIWA dan RAGA". Dengan disahkannya UU Disabilitas oleh DPR menjadi hal yang menggembirakan sebagai perlindungan bagi penyandang disabilitas terutama bagi ODGJ dan bagi lembaga-lembaga berinisiatif memberikan kemudahan akses dan fasilitas yang dibutuhkan oleh penyandang disabilitas khususnya ODGJ. Dan dalam program Gerakan Masyarakat Hidup Sehat (GERMAS) tahun 2016 dengan pendekatan keluarga bahwa dalam indikator capaian keluarga sehat yaitu salah satunya penderita gangguan jiwa mendapatkan pengobatan dan tidak diterlantarkan.

Berdasarkan hasil pengamatan di kelurahan Magelang Tengah, kecamatan Magelang Tengah, kota Magelang. kasus gangguan jiwa di kelurahan Magelang Tengah, kecamatan Magelang Tengah, kota Magelang relatif masih tinggi. Hal ini ditandai dengan banyaknya data yang diperoleh dari Puskesmas Magelang Tengah yaitu 
Available online at https://jurnal.stmikroyal.ac.id/index.php/jurdimas

sebanyak 18 Orang dengan gangguan jiwa (ODGJ) (Ubaidillah, 2017).

Akan tetapi, bentuk pelayanan dan tingkat kepedulian masyarakat yang diberikan pada pasien gangguan jiwa masih rendah. Dibuktikan dengan belum adanya kelompok yang peduli terhadap kondisi pasien gangguan jiwa di kelurahan Magelang, kecamatan Magelang, kota Magelang. Dengan adanya kasus tersebut, maka salah satu cara yang dapat dilakukan untuk mencegah diskriminasi dan meningkatkan kemandirian penyandang disabilitas yaitu dengan Optimalisasi Kader Kesehatan Jiwa. Pada kelurahan Magelang Tengah, kecamatan Magelang Tengah, kota Magelang sudah terdapat kader kesehatan yang aktif namun dalam pelaksanaannya belum merambah sampai ke kesehatan jiwa, sehingga kader yang sudah ada perlu dilath agar menjadi Kader Kesehatan Jiwa (KKJ) .

Dengan adanya kader kesehatan jiwa yang optimal diharapkan kader dapat mengubah pola hidup dan perilaku ODGJ, pengasuh dan masyarakat. Kader kesehatan jiwa dapat berpengaruh dalam pendeteksian sekaligus meningkatkan peran perawat dalam merawat ODGJ sekaligus memberikan pengetahuan bagi pengasuh untuk peduli pada kebutuhan ODGJ yaitu kebutuhan akan obat, peran keluarga, kebutuhan religi dan kebutuhan sosial. Untuk memudahkan pemantauan warga binaan perlu adanya kegiatan yang dapat terus menerus dilaksanakan oleh kader kesehatan jiwa di masyarakat untuk memantau kesehatan ODGJ serta menjalin kearifan pengasuh dan masyarakat yaitu dengan pembentukan Posyandu Jiwa.

Posyandu jiwa yaitu suatu pos yang memberikan pelayanan secara menyeluruh dan terpadu kepada masyarakat khususnya dalam hal kesehatan jiwa. Kegiatan posyandu dijadikan sebagai bentuk tindak lanjut program optimalisasi kader. Sistem pelaksanaan posyandu jiwa sama dengan sistem posyandu balita maupun lansia dengan sistem lima meja, namun yang membedakan yaitu isi dari pelaksanaan setiap meja. Meja pertama, diawali dengan pendaftaran pasien. Meja kedua, penimbangan pasien, pengukuran tekanan darah, dan pengecekan obat. Meja ketiga, konsultasi kesehatan jiwa pasien dan keluarga. Meja keempat, penyuluhan kepada pasien dan keluarga secara berkelompok. Meja kelima, pelayanan kesehatan dan rehabilitasi pasien.

\section{METODE}

Lokasi pada pengabdiian masyarakat ini yaitu kelurahan Magelang, kecamatan Magelang Tengah, kota Magelang dengan jumlah responden 15 Kader jiwa dan jumlah ODGJ 34 orang dan dengan resiko 2 orang. Metode yang di gunakan adalah pendampingan yang di fokuskan dalam kesehatan jiwa dan membantu para kader yang sudah di beri pelatihan tentang kesehatan jiwa untuk meningkatan keterampilan yang dimiliki dan yang sudah di berikan oleh petugas puskesmas Magelang Tengah.

Adapun Tahapan pelaksanaan program pengabdian masyarakat dalam hal penyelesaian masalah seperti pada gambar 1. 
Jurdimas (Jurnal Pengabdian Kepada Masyarakat) Royal

Vol. 3 No. 2, Juli 2020, hlm. 115 - 122

DOI: https://doi.org/10.33330/jurdimas.v3i2.616

Available online at https://jurnal.stmikroyal.ac.id/index.php/jurdimas

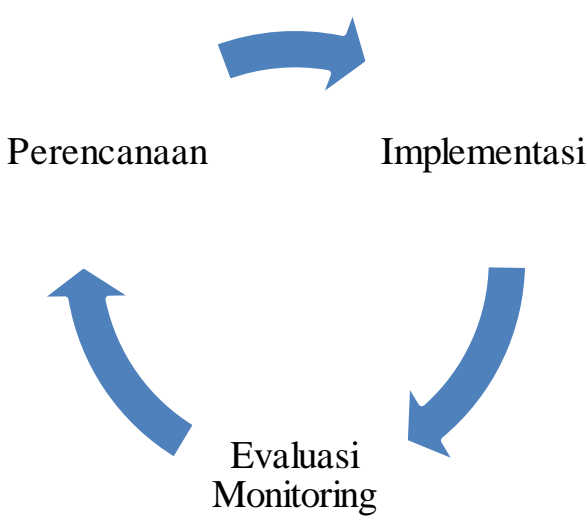

Gambar 1. Alur pelaksanaan program

Pertama dimulai dengan perencanan dalam perencanaan dilakukan persiapan dan perencanaan jadwal kegiatan pelaksanaan aksi. Kemudian dilakukan implementasi program dalam implementasi program dilakukan deteksi dini dan sosialisai. Lalu dilakukan evaluasi monitoring dtujukan guna mendapatkan jumlah orang dengan gangguan jiwa dikelurahan magelang. kelanjutan program, dilanjutkan oleh KPSI dan mitra puskesmas magelang.

Bersamaan dengan mendampingi kader mahasiswa juga melakukan deteksi dini kepada setiap warga yang ada di kelurahan Magelang disetiap RW. Setelah melakukan deteksi dini mahasiwa selanjutnya melakukan sosialisasi tentang kesehatan jiwa pada masyarakat yang berisi tentang dasar kesehatan jiwa, tanda-tanda orang dengan gangguan jiwa dan cara rujukan untuk orang dengan gangguan jiwa.

\section{PEMBAHASAN}

Ada 4 kegiatan utama dalam menyelesaikan masalah:
1) Pelatihan

Tahap Pertama yaitu Pelatihan Kader Kesehatan Jiwa yang di jadikan sebagai bentuk awal pelaksanaan kegiatan. Kegiatan tersebut dilaksanakan pada hari Rabu, 19 februari 2020 di aula puskesmas magelang tengah. Kegiatan pertama meliputi, pemaparan materi oleh narasumber dari KPSI magelang, ketua perawat jiwa puskesmas magelang tengah, Ketua KPSI Magelang, dan calon kader kesehatan jiwa Per RW dengan delegasi sebanyak 1 hingga 2 orang. Dalam kegiatan tersebut bertujuan untuk pelatihan kader kesehatan jiwa, dalam program pengabdian pada masyarakat terpadu tahun 2020 .

Dari pihak Fakultas kesehatan universitas Muhammadiyah Magelang dihadiri oleh dosen pendamping yang mengesahkan dan menyetujui dimulainya program. Dalam kegiatan ini disepakati 4 hal, yaitu penentuan program yang dilaksanakan berkaitan dengan program kesehatan jiwa dengan rentang waktu efektif pelaksanaan selama 1 bulan dalam 3 tahapan meliputi pelatihan, pendampingan dan evaluasi.

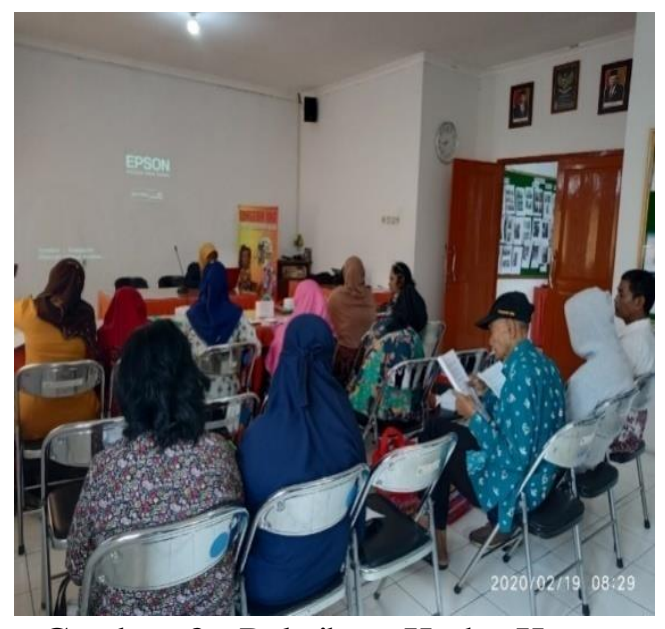

Gambar 2. Pelatihan Kader Keswa 
Available online at https://jurnal.stmikroyal.ac.id/index.php/jurdimas

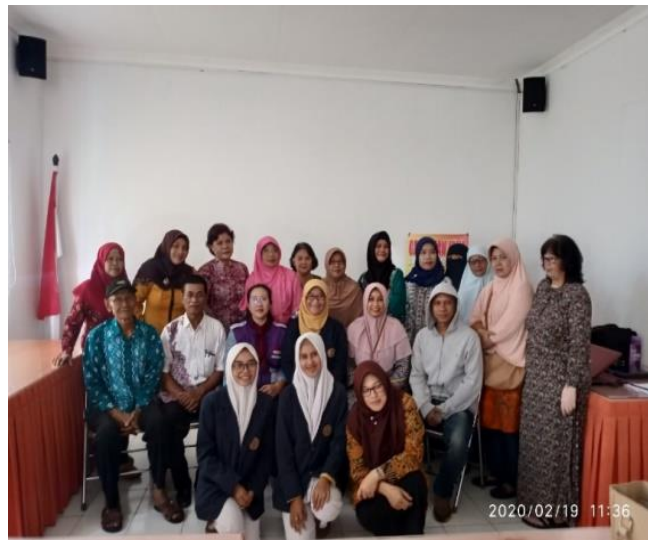

Gambar 3. Dokumentasi PKM

2) Pendampingan

Kegiatan Kedua yaitu Pelaksanaan pendampingan kader kesehatan jiwa dilaksanakan di wilayah setiap RW. Mulai dari tanggal 22 Februari 2020 sampai 18 maret 2020, kegiatan ini mendampingi kader kesehatan jiwa untuk deteksi di setiap RW. Dalam kegiatan ini bertujuan untuk mengetahui berapa jumlah orang dengan gangguan jiwa yang belum terdaftar atau rutin periksa di Puskesmas Magelang Tengah dan juga melatih kader agar bisa mandiri. Implementasi dan pendampingan kader kesehatan jiwa yang dilakukan di masyarakat meliputi sosialisasi masyarakat, deteksi dini, pemetaan rumah ODGJ, Psikoedukasi keluarga:

a) Sosialisasi dilakukan per RW selama 1 hari yang dihadiri oleh caregiver maupun masyarakat. Kegiatan ini dilakukan oleh kader kesehatan. Dengan materi yang disampaikan dalam sosialisasi ini adalah pengenalan program dan pengenalan kesehatan jiwa.

b) Deteksi dini dilakukan oleh kader secara mandiri ditiap dusun untuk mengetahui jumlah ODGJ yang ada di Rwnya yang dibagi kedalam 3 bagian, yaitu orang dengan sehat, risiko, dan gangguan jiwa/sakit.
Jumlah ODGJ yang ditemukan kader setelah dilakukan deteksi dini yaitu sebanyak 34 ODGJ dan 2 dengan risiko.

c) Pemetaan letak rumah penyandang disabilitas tiap RW bertujuan agar memudahkan jika akan dilakukan kunjungan rumah oleh kader, pihak puskesmas, maupun tim KPSI. Bentuk pemetaan letak rumah tersebut berupa alamat rumah lengkap yang terdapat di setiap RW, puskesmas.

d) Alisasi tentang kesehatan jiwa yang dilakukan di setiap RW, sosialisasi ini dihadiri oleh Tim PPMT, kader kesehatan jiwa dan Ibu-ibu PKK.

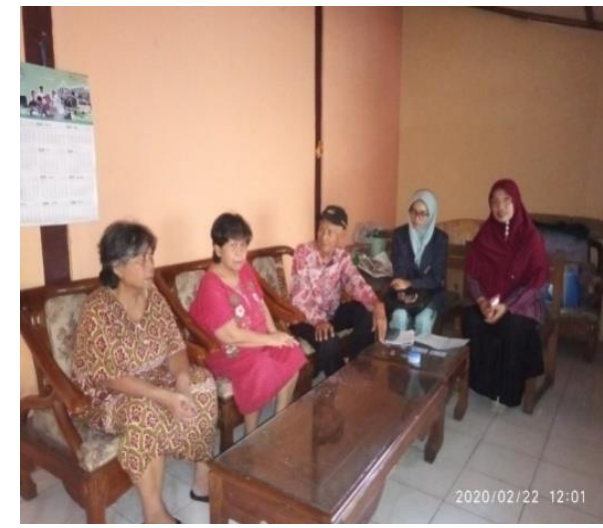

Gambar 4. Pendampingan Kader Keswa.( Kel. Magelang Tengah, 2020)

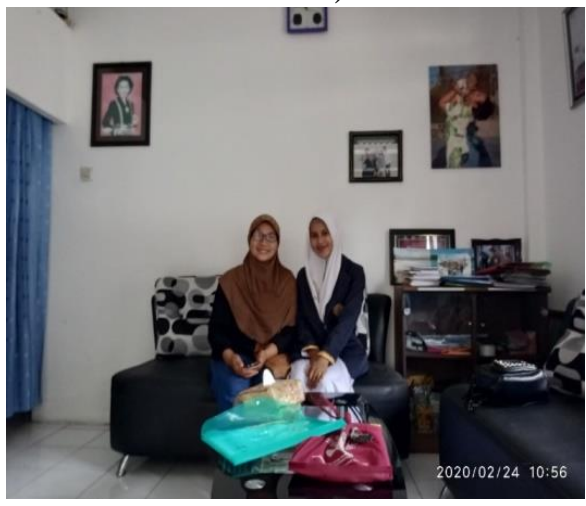

Gambar 5. Pendampingan Kader Keswa ( Kel. Magelang Tengah, 2020) 
Available online at https://jurnal.stmikroyal.ac.id/index.php/jurdimas

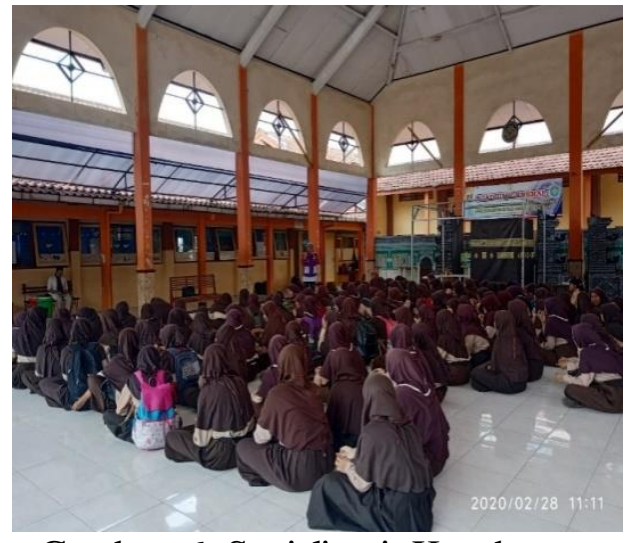

Gambar 6. Sosialisasi Kesehatan Jiwa

( Kel. Magelang Tengah, 2020)

3) Tahap Evaluasi dalam tahap evaluasi ini dilakukan evaluasi dalam dua hal. Evaluasi pertama adalah evaluasi pada hasil kegiatan yang telah dilakukan oleh kader, serta pengetahuan yang suduah diperoleh keluarga untuk mengimplementasikannya kepada ODGJ. Sedangkan evaluasi yang kedua adalah evaluasi berdasarkan pelaksanaan program yang sudah dicapai oleh kader dan tim KPSI.

4) Tahap Pendampingan Kader dan evaluasi, dilakukan dengan mengetahui kekurangan dalam pelaksanaan program yaitu masih kuatnya stigma beberapa keluarga, sehingga butuh pendekatan khusus. Melalui proses evaluasi, kekurangan yang terjadi dalam pelaksanaan program dapat diperbaiki menjadi lebih baik. Tahap ini dilakukan oleh Tim Peneliti (Mahasiswa dan Dosen) bersama pihak masyarakat.

\section{Evaluasi dan Keberlanjutan:}

Program yang telah dilaksanakan di Kelurahan Magelang telah berjalan selama 1 bulan. Dari pelaksanaan kegiatan diatas terdapat beberapa point yang dilaksanakan dalam program yang telah diuraikan di atas, dengan penjabaran hasil dan tindak keberlanjutan program, yaitu:

1) Terbentuknya kesepakatan antar pihak dan elemen terkait untuk mendukung berjalannya program, perencanaan Peningkatan Kesehatan Jiwa Melalui Peran Kader Menuju Kelurahan Siaga Sehat Jiwa pada, 28 Januari 2020. Adanya pihak-pihak yang berkomitmen untuk melanjutkan program kesehatan jiwa oleh kader kesehatan jiwa terlatih, puskesmas Magelang tengah, Tim pengembangan keperawatan jiwa UMM magelang sebagai fasilitator.

2) Terbentuknya 4 kesepakatan bersama dengan masyarakat, yaitu waktu pelaksanaan program, penentuan program, pembentukan kader, dan pembagian wilayah. Program yang dilaksanakan berkaitan dengan program kesehatan jiwa dalam rentang waktu selama 1 bulan. Dan terbentuknya kader kesehatan jiwa dari 12 RW sejumlah 15 orang yang menjalankan program kesehatan jiwa. Adanya mitra dari puskesmas Magelang Tengah dan KPSI yang dapat membantu dalam pelaksanaan di Kelurahan Magelang.

3) Adanya peningkatan pemahaman kader tentang tingkat pengetahuan dan sikap kader. Dari materi yang telah disampaikan oleh beberapa narasumber tentang peran kader, teknik wawancara, dan deteksi dini, kader dapat mempraktekkan secara langsung melalui simulasi teknik wawancara dan deteksi dini setelah pelatihan kader. Kader Kesehatan Jiwa yang telah terbentuk dan terlatih mengimplementasikan pengetahuan yang sudah diberikan selama pelatihan kepada keluarga, ODGJ dan masyarakat. 
Available online at https://jurnal.stmikroyal.ac.id/index.php/jurdimas

4) Terdapat peningkatan pemahaman oleh keluarga dan masyarakat tentang orang dengan gangguan jiwa Adanya komitmen bersama dari keluarga dan masyarakat untuk memberikan pelayanan kesehatan kepada ODGJ.

5) Adanya peningkatan jumlah ODGJ setelah dilakukan deteksi dini oleh kader kesehatan jiwa dengan jumlah ODGJ sebanyak 34 orang, dan 2 orang dengan resiko. Dengan adanya peningkatan jumlah ODGJ, maka dilakukanlah pemetaan untuk mempermudah kader untuk mengetahui letak rumah ODGJ saat kunjungan rumah dalam memberikan penyuluhan dan dilakukannya psikoedukasi keluarga bersama caregiver.

6) Terbentuknya buku sebaran kasus ODGJ per RW yang dibawa oleh kader kesehatan jiwa di setiap $\mathrm{Rw}$ Adanya program kunjungan rumah oleh kader dan petugasan kesehatan secara terencana dan berkala.

7) Adanya peningkatan pemahaman bagi caregiver tentang kesehatan jiwa. Adanya komitmen caregiver untuk tidak menelantarkan ODGJ dengan memberikan pengobatan ke pelayanan kesehatan seperti Puskesmas atau RSJ.

Di dapatkannya peningkatan jumlah ODGJ di Kelurahan Magelang yang terbagi dalam 3 bagian yaitu orang dengan sehat, resiko, dan gangguan jiwa/sakit. Jumlah sebanyak 34 ODGJ dan 2 orang dengan resiko. Dari berjalannya program, kader sudah mengalami peningkatakan pada tingkat pengetahuan dan sikap kader, namun ada beberapa kader yang belum optimal dalam melaksanakan perannya dikarenakan dikhawatirkan respon dari warga binaan yang buruk. Sehingga hal tersebut menyebabkan kurangnya partisipasi keluarga dalam melaksanakan program dari kader kesehatan jiwa. Hal yang dapat dilakukan untuk menghilangkan stigma kader kepada warga binaan dengan cara meminta bantuan kepada tokoh masyarakat ataupun tokoh agama untuk memebrikan pengetahuan dan melakukan pendekatan kepada keluarga.

\section{SIMPULAN}

Kegiatan peningkatan kesehatan jiwa melalui peran kader menuju kelurahan siaga sehat jiwa telah terlaksana yang dimulai dari tanggal 19 Februari 2020 hingga 18 Maret 2020 yang dimulai dengan pembentukan kader serta pemberian pelatihan dan pendampingan kader terkait ODGJ berdampak positif terhadap kinerja kader jiwa dan pelayanan kepada ODGJ. namun masih perlu penguatan motivasi bagi para kader juga berbagai kegiatan dalam upaya peningkatan kemampuannya. Peran aktif mitra juga perlu terus ditingkatkan agar dapat mewujudkan tujuan penanganan masalah kesehatan jiwa di Kelurahan Magelang.

\section{UCAPAN TERIMAKASIH}

Terima Kasih kepada Lembaga Penelitian dan Pengabdian Masyarakat (LPPM) Universitas Muhammadiyah Magelang dalam kegiatan Pengabdian pada Masyarakat Terpadu (PPMT) Tahun 2020, Puskesmas Magelang Tengah sebagai fasilitator dalam proses kegiatan dan Kelurahan Magelang Kecamatan Magelang Tengah sebagai tempat pelaksanaan kegiatan serta KPSI sebagai pendukung keberlanjutan kegiatan. 
Jurdimas (Jurnal Pengabdian Kepada Masyarakat) Royal

Vol. 3 No. 2, Juli 2020, hlm. 115 - 122

DOI: https://doi.org/10.33330/jurdimas.v3i2.616

Available online at https://jurnal.stmikroyal.ac.id/index.php/jurdimas

\section{DAFTAR PUSTAKA}

Cheung, K., Taillieu, T., Turner, S., Fortier, J., Sareen, J., Macmillan, H. L., Boyle, M. H., \& Tracie, O. A. (2017). Child Abuse \& Neglect Relationship and community factors related to better mental health following child maltreatment among adolescents. 70(January), 377-387.

https://doi.org/10.1016/j.chiabu.201 7.06.026

Kiesswetter, E., Hengeveld, L. M., Jf, B., Volkert, D., \& Visser, M. (2019). Oral health determinants of incident malnutrition in community-dwelling older adults. Journal of Dentistry, 85(May), 7380.

https://doi.org/10.1016/j.jdent.2019. 05.017

Ubaidillah, Pinilih, S. S., Astuti, R. T., \& Wijayanti, K. (2017). Pengaruh Pelatihan Terapi Suportif Kelompok Terhadap Peningkatan Peran Kader Kesehatan Jiwa di Desa Paremono ,. Community Environment, 499-512.
Komarudin, C. (2016). Kelompok kader penanganan gangguan jiwa Fakultas Ilmu kesehatan Universitas Muhammadiyah Jember Email: komarudin@unmuhjember.ac.id Kesehatan mental di Indonesia selama ini relatif terabaikan, padahal penurunan produktifitas akibat gangguan kesehatan jiw. Pengabdian Masyarakat Ipteks, 2(2), 57-64.

Hidayat, E., \& Santoso, A. B. (2019). Upaya Peningkatan Kesehatan Jiwa Masayarakat melalui Pelatihan Kader Kesehatan Jiwadi Wilayah KerjaPuskesmas Sunyaragi Kota Cirebon. Edukasi Masyarakat Sehat Sejahtera (EMaSS): Jurnal Pengabdian Kepada Masyarakat, 1(1), 42-49. https:/doi.org/10.37160/emass.v1il.18 9

JIWA, P. K. J. M. P. K. K. (2019). Ari Dwi Jayanti. 2(1), 33-40.

Taty Hernawaty, Dyah Setyorini, Indra Maulana, H. S. A. (2018). Pembentukan Kader Kesehatan Jiwa Di Kabupaten Pangandaran. Jurnal Pengabdian Kepada Masyarakat, 2(9). https://doi.org/10.1017/CBO97811074 15324.004 